\title{
Manejo inicial del aborto
}

\author{
Initial management of abortion \\ Tratamento inicial do aborto
}

Cecilia Larroca ORCID: 0000-0001-8040-9460

Ginecotocológica B. Hospital de

Clínicas. UdelaR.

Virginia Chaquiriand ORCID: 0000-0003-1509-2780

Ginecóloga. Ex. Profesor Adjunta Clínica Ginecotocológica B. Hospital de Clínicas. UdelaR.

Resumen: Se presenta una puesta a punto sobre las definiciones de aborto, pérdida recurrente de embarazo, aborto espontáneo y espontáneo precoz. Las anormalidades en el crecimiento y desarrollo del embrión son las causas más frecuentes de pérdida de la gestación tanto subclínica como clínicamente reconocibles. Las causas del aborto espontáneo y de pérdida recurrente de embarazo son múltiples, entre las más frecuentes se encuentran alteraciones genéticas, endocrinopatías, infecciones, trombofilias adquirídas y causas anatómicas. Se realiza la revisión sobre el asesoramiento para parejas que sufren estas patologías.

\section{Palabras clave: aborto}

Abstract: A refinement is presented on the definitions of abortion, recurrent pregnancy loss, spontaneous abortion and early spontaneous abortion. Abnormalities in the growth and development of the embryo are the most frequent causes of pregnancy loss both subclinically and clinically recognizable. The causes of spontaneous abortion and recurrent pregnancy loss are multiple, among the most frequent are genetic alterations, endocrinopathies, infections, acquired thrombophilias and anatomical causes. A review of counseling for couples suffering from these pathologies is carried out.

Key words: abortion

Resumo: É apresentado um ajuste fino nas definições de aborto, perda recorrente de gravidez, aborto espontâneo e aborto espontâneo precoce. Anormalidades no crescimento e desenvolvimento do embrião são as causas mais frequentes de perda de gravidez, tanto subclínica quanto clinicamente reconhecíveis. As causas do aborto espontâneo e da perda gestacional recorrente são múltiplas, entre as mais frequentes estão as alterações genéticas, endocrinopatias, infecções, trombofilias adquiridas e causas anatômicas. É realizada uma revisão do aconselhamento para casais que sofrem dessas patologias.

Palavras chave: aborto 


\section{Definiciones}

\section{a) Aborto}

Se llama aborto a toda interrupción espontánea o provocada del embarazo antes de las 20 semanas de amenorrea, o a la expulsión de un producto gestacional con un peso menor a 500 gramos. Según la edad gestacional, se puede clasificar en, precoz cuando ocurre antes de las 12 semanas, y tardío, cuando ocurre después de las 12 semanas.

Según el momento del desarrollo en el cual se produce la pérdida, se puede clasificar en preembrionaria (hasta las semanas 5-6 contando desde la FUM), embrionaria (desde la semana 7 a la semana 10) o fetal (a partir de la semana 11 a la semana 20) y óbito a partir de la semana 20.

\section{b) Pérdida recurrente del embarazo}

Se considera pérdida recurrente del embarazo (PRE) la presencia de 3 o más pérdidas consecutivas de embarazos confirmados menores de 20 semanas. Algunos autores incluyen pérdidas posteriores a las 20 semanas y otros consideran PRE con 2 o más pérdidas. Estas pérdidas deben estar documentadas por histología o ecografía (cuando se constata saco gestacional intrauterino $)^{1-3}$.

\section{c) Aborto espontáneo}

El aborto es la interrupción del embarazo antes de la viabilidad fetal. La viabilidad fetal es un concepto que involucra aspectos epidemiológicos antropométricos y clínicos. Se considera viabilidad fetal cuando presenta edad gestacional de 20 semanas y el peso fetal es de $500 \mathrm{gr}$ (OMS). La viabilidad clínica es un concepto más amplio que involucra la capacidad de la medicina actual de prestar asistencia contra la prematurez extrema, y está determinada por la madurez anátomo funcional del pulmón, o sea la capacidad de intercambio gaseoso pulmonar, que ocurre aproximadamente entre las 24 a 26 semanas de gestación ${ }^{4}$.

\section{d) Aborto espontáneo precoz}

La pérdida precoz del embarazo o aborto espontáneo precoz, se define como un embarazo intrauterino con un saco gestacional vacío (huevo anembrionado) o un embrión o feto sin actividad cardiaca antes de las 12 semanas de edad gestacional.

\section{Incidencia y factores de riesgo}

El aborto espontáneo tiene una incidencia del 10 a 20\% de todos los embarazos clínicos, es decir cuando se constató un saco gestacional intrauterino, siendo esta tasa tres veces mayor en embarazos tempranos no reconocidos. El $80 \%$ de todos los abortos espontáneos ocurren en el primer trimestre.

Las anormalidades en el crecimiento y desarrollo del embrión son las causas más frecuentes de pérdida de la gestación tanto subclínica como clínicamente reconocibles. Cerca de la mitad de los especímenes de abortos que ocurren antes de la primera mitad de la gestación y una tercera parte de los que ocurren antes o a las 8 semanas de gestación son anembriónicos. La presencia de embrión o feto identificable se encuentra en el 50 a $60 \%$ de especímenes de abortos del primer trimestre o del inicio del segundo trimestre, pero únicamente la mitad de éstos son normales y el resto son dismórficos, con crecimiento disminuido o con productos muy macerados como para poder examinarse.

El factor de riesgo más común identificado en estas pacientes son la edad materna avanzada y el antecedente de un aborto espontáneo precoz (aborto clínico). La frecuencia de abortos espontáneos clínicos para mujeres entre 20 y 30 años es de un 9 a un $17 \%$, aumentando a un $20 \%$ a los 35 años, y luego aumenta a un $40 \%$ a los 40 años y a un $80 \%$ a los 45 años. En mujeres que no han tenido hijos, después de un primer aborto la probabilidad de un segundo aborto es de un $19 \%$, si ha tenido dos abortos previos esta cifra aumenta a $35 \%$ y si han tenido tres abortos esta probabilidad asciende a $47 \%{ }^{4-7}$. 


\section{Etiología}

Las causas del aborto espontáneo son múltiples y entre las más frecuentes se encuentran:

\section{a) Causas genéticas}

Aproximadamente el 30 al $50 \%$ de los abortos espontáneos son citogenéticamente anormales; las anormalidades en el cariotipo llegan a ser hasta del $50 \%$ a las $8-11$ semanas de gestación y del 30\% a las 16-19 semanas de gestación. Las causas genéticas, siendo estas las más frecuentes en los abortos tempranos, producen huevos aberrantes, son resultado de alteraciones en la meiosis, sus progenitores tienen cariotipos normales y las anomalías más frecuentes son las trisomía autosómica, la triploidia, la monosomía X, la tetraploidia y las alteraciones en la reordenación de cromosomas. Estas anomalías se encuentran en el $80 \%$ de los huevos aberrantes y en 5 a $10 \%$ de los abortos en los que hay feto.

\section{b) Endocrinopatías}

La diabetes mellitus, los distiroidismos y la deficiencia de progesterona o fase lútea insuficiente y síndrome de ovario poliquístico son las causas más frecuentes. La obesidad es un factor de riesgo independiente para abortos espontáneos y peores resultados obstétricos.

\section{c) Causas infecciosas}

Infecciones bacterianas como Micoplasma hominis y Ureaplasma urealyticum, infecciones parasitarias como toxoplasmosis e infecciones por virus como herpes, citomegalovirus y rubéola son las más destacadas.

\section{d) Causas anatómicas}

Las anomalías anatómicas del útero causan un 10 a 15\% de todos los abortos con desarrollo fetal adecuado. Pueden ser secundarias a malformaciones congénitas, sinequias uterinas, miomatosis uterina, incompetencia cérvico ístmica, entre otras.

Otras causas, son las inmunológicas como el síndrome antifosfolípidico, enfermedades maternas crónicas, exposición a teratógenos y iatrogénicas ${ }^{4-6}$.

\section{Conducta y asesoramiento}

El aborto espontáneo precoz es una complicación frecuente del embarazo, siendo su causa más frecuente la presencia de anomalías cromosómicas en progenitores con cariotipo normal, siendo el principal factor de riesgo la edad materna avanzada y el antecedente de un aborto espontáneo previo. Esto quiere decir que la gran mayoría de los abortos espontáneos precoces ocurren en pacientes sanas, sin factores de riesgo.

Cuando nos enfrentamos a una paciente con el antecedente de un aborto espontáneo precoz es fundamental realizar una correcta historia clínica para valorar la presencia de factores de riesgo y en caso de no existir los mismos no está indicada la realización de estudios paraclínicos. Luego de una pérdida precoz en forma rutinaria, no se recomienda estudio cromosómico materno ni fetal ni tampoco síndrome antifosfolipídico obstetrico o trombofilias hereditarias ${ }^{5,6}$.

La PRE afecta hasta un $5 \%$ de las parejas, determinando frecuentemente frustración tanto a la pareja como al equipo médico y esto es, debido a que es poco frecuente encontrar una causa tratable porque la PRE tiene una naturaleza multifactorial. Si bien hay múltiples etiologías, solo un pequeño grupo de estas están validadas por estudios bien dirigidos y aceptadas por la mayoría de los expertos. A continuación se detallan las causas más frecuentes, pero es importante destacar que en hasta un $75 \%$ de los casos no se identifica una causa clara ${ }^{8,9}$.

\section{a) Causa genética: anomalía de los cariotipos paternos}

Las translocaciones o inversiones cromosómicas balanceadas se encuentran en uno de los progenitores en el $5 \%$ de las parejas con PRE. Esto es 5 a 10 veces más frecuente que en la población general, lo que sugiere que se asocia con un riesgo aumentado de pérdida de embarazo. Es más frecuente que ocurra en la mujer que en el hombre. La tasa de nacidos vivos en padres con reordenamientos cromosómicos balanceados es de un 60 a $70 \%$ sin tratamiento, variando los resultados según la anomalía específica. 
Por otro lado, la tasa de nacidos vivos con cromosomas anormales o arreglos no balanceados es de un 1\%. La importancia del estudio del cariotipo parental en parejas con PRE no es claro, principalmente por la falta de un tratamiento efectivo, a pesar del beneficio teórico de la realización de fertilización in vitro con diagnóstico genético pre-implantacional, sabiendo que el pronóstico es razonablemente bueno sin tratamiento ${ }^{8-10}$.

La sociedad española de ginecología recomienda con un nivel de evidencia B, el estudio de cariotipos paternos y cariotipo de restos ovulares y cribado genético preimplantacional a: $\geq$ 2 abortos en pacientes de 35 años o más, $\geq 3$ abortos en menores a 35 años, $\geq 2$ abortos en pacientes menores a 35 años con infertilidad asociada.

\section{b) Trombofilias adquiridas: síndrome antifosfolípidico obstétrico}

Es una enfermedad autoinmune caracterizada por trombosis venosa o arterial y malos resultados obstétricos, y es una causa mundialmente aceptada de pérdida recurrente del embarazo. Entre un 5 y un 15\% de mujeres con PRE tienen anticuerpos antifosfolípidos positivos en comparación con un 2 a $5 \%$ de mujeres sin pérdidas de embarazo.

\section{c) Alteraciones anatómicas uterinas}

Estudios reportan malformaciones uterinas entre un 10 y un $20 \%$ de mujeres con PRE. La causa de pérdidas precoces en estas pacientes podría ser por producirse la implantación en un septo poco vascularizado, sin embargo este mecanismo solo está avalado por evidencia indirecta. Estudios en modelos genéticos también sugieren que la disregulación de tejidos endometriales y estromales podrían jugar un rol en las pérdidas asociadas a malformaciones uterinas.

Por otro lado, la relación entre anomalías uterinas adquiridas como miomas, adherencias endometriales o pólipos endometriales no está bien establecida. La recomendación para el estudio de las causas anatómicas es la realización de pruebas de imagen (ecografía 3D, histerosalpingografia, resonancia magnética). La histeroscopia, tanto como método diagnóstico complementario, como terapéutico cuando se constata un problema anatómico. Una vez realizado el diagnóstico se recomienda intervenir las patologías que han sido relacionadas con aborto recurrente (otras han sido únicamente asociadas con aborto esporádico o con infertilidad, como sinequias, pólipos o adenomiosis). Los úteros septados y sub-septados, los úteros hipoplasicos y úteros en $\mathrm{T}$, son las patologías que han presentado mayor asociación con aborto recurrente, de las qué hay más datos sobre la mejora del pronóstico reproductivo luego de su corrección. Sin embargo, no hay ningún estudio aleatorizado hasta el momento que haya demostrado la mejora en las tasas de recién nacido vivo tras su corrección en pacientes con PRE ${ }^{8,9}$.

\section{Bibliografía}

1- Practice Committee of the American Society for Reproductive Medicine. Definitions of infertility and recurrent pregnancy loss: a committee opinion. Fertil Steril. 2013 Jan;99(1):63. doi: 10.1016/j. fertnstert.2012.09.023.

2- Page JM, Silver RM. Genetic Causes of Recurrent Pregnancy Loss. Clin Obstet Gynecol. 2016 Sep;59(3):498-508. doi: 10.1097/GRF.0000000000000217

3- Stevenazzi M, Guillermo C coord. Trombofilia y Mujer [Internet] Montevideo: Universidad de la Republica; Facultad de Medicina; Cátedra Hematología; 2014 [acceso marzo 2021]. Disponible en: http://www.shu.com.uy/images_hematologia/trombofilia_mujer/pautas 2014.pdf.

4- Neira Miranda J. Aborto, aspectos clínicos y epidemiológicos, ARS MEDICA Rev Cien Méd. 2016; 15(2), 64-69. https://doi.org/10.11565/arsmed.v31i1.290.

5- The American College of Obstetricians and Gynecologists Practice Bulletin no. 150. Early pregnancy loss. Obstet Gynecol. 2015 May;125(5):1258-1267. doi: 10.1097/01.AOG.0000465191.27155.25.

6- ACOG Practice Bulletin No. 200 Summary: Early Pregnancy Loss. Obstet Gynecol. 2018 Nov;132(5):1311-1313. doi: 10.1097/AOG.0000000000002900.

7- Kolte AM, Bernardi LA, Christiansen OB, Quenby S, Farquharson RG, Goddijn M, et al; ESHRE Special Interest Group, Early Pregnancy. Terminology for pregnancy loss prior to viability: a consensus statement from the ESHRE early pregnancy special interest group. Hum Reprod. 2015 Mar;30(3):495-8. doi: 10.1093/humrep/deu299. 
8- Hatasaka HH. Recurrent miscarriage: epidemiologic factors, definitions, and incidence. Clin Obstet Gynecol. 1994 Sep;37(3):625-34. doi: 10.1097/00003081-199409000-00016.

9- Kaiser J, Branch DW. Recurrent Pregnancy Loss: Generally Accepted Causes and Their Management. Clin Obstet Gynecol. 2016 Sep;59(3):464-73. doi: 10.1097/GRF.0000000000000214

10- Tunç E, Tanriverdi N, Demirhan O, Süleymanova D, Cetinel N. Chromosomal analyses of 1510 couples who have experienced recurrent spontaneous abortions, Reprod. Biomed. Online. 2016; 32 : 414-419. https://doi.org/10.1016/j.rbmo.2016.01.006.

\section{Aporte de cada autor al trabajo}

Cecilia Larroca: Concepción y diseño del trabajo, recolección de datos, redacción y revisión crítica del manuscrito.

Virginia Chaquiriand: Concepción y diseño del trabajo, recolección de datos, redacción y revisión crítica del manuscrito. 